\title{
TANGential LASER MACHINING USING FS-PUlSEd LASER
}

\author{
Simon Syrovatka, Adam Cermak, Pavel Kozmin, \\ Ondrej Marsalek \& Tomas Zatloukal
}
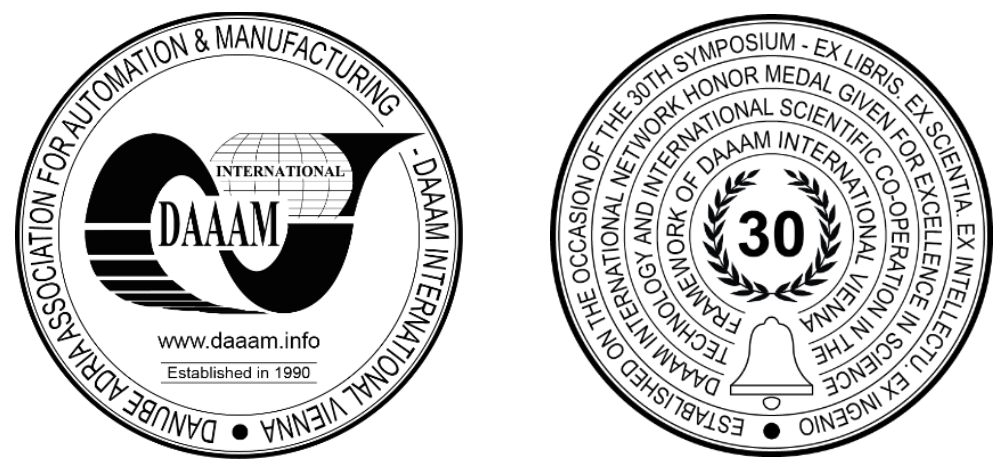

This Publication has to be referred as: Syrovatka, S[imon]; Cermak, A[dam]; Kozmin, P[avel]; Marsalek, O[ndrej] \& Zatloukal, T[omas] (2021). Tangential Laser Machining Using Fs-pulsed Laser, Proceedings of the 32nd DAAAM International Symposium, pp.0685-0691, B. Katalinic (Ed.), Published by DAAAM International, ISBN 978-3-90273433-4, ISSN 1726-9679, Vienna, Austria

DOI: 10.2507/32nd.daaam.proceedings.096

\begin{abstract}
For the production of very small and precise rotating parts, it is often necessary to use the best of conventional and unconventional machining methods. Laser machining is an unconventional machining method that is increasingly used because with its use it is possible to produce very precise and miniature shapes that are not thermally affected. The aim of this article is to explore the technology of laser tangential machining (which is inspired by the classical machining turning process) on a used femtosecond laser system. And find out the ideal setting for the laser tangential machining process to obtain the best surface roughness and the highest process productivity.
\end{abstract}

Keywords: laser; laser turning; tangential machining; surface roughness

\section{Introduction}

These days the laser machining technology represents one of the most advanced technologies in the mechanical industry. There are a number of different laser systems that are used during laser machining. These devices can be divided according to their average laser power $P_{a v}$, size of the wavelength $\lambda$, length of the laser pulses $\tau_{p}$, type of the laser source, etc. [1]. However, this article is focusing on the lasers with the ultrashort duration of the laser pulses namely pulses with a duration of the order of femtoseconds. The advantage of these lasers is that due to the ultra-short lengths of the laser pulses and the large energy in one pulse, the material does not melt, but the ablation of material is happening. This is desirable because machining with these lasers does not significantly thermally affect the surrounding material [2]. The femtosecond lasers are usually used for producing small shapes or parts because of the diameter of the laser spot which value is commonly in the tens of microns.

Nowadays is it more usually to reduce the dimensions of products to such an extent that sometimes it is not even enough to use the process of classical radial laser ablation for production. In such cases, a tangential laser process can be used. This is a process where the laser beam does not impact perpendicular to the workpiece surface, but tangentially[3]. This type of process can be also used in the production of rotating products where the laser beam moves around the axis of the workpiece and impinges tangentially on the workpiece while the workpiece is rotating around its axis [3], [4]. This process is closely linked to the conventional method of turning. 
It is also possible that the laser beam is not tangential to the workpiece but directly perpendicular to the workpiece surface, which can result in greater material removal and a shorter process time. The output qualities which are important for customers can be the surface roughness and shape accuracy of the product. These qualities depend on several laser parameters which are investigated in scientific articles. For example, Kibra et al. [6] made an experiment with a nanosecond pulse laser which goal was to observe the relations between overlaps of laser spots and surface roughness during different pulses frequencies and velocities of rotation of the workpiece. They also found out that with increasing percentage overlap of laser spots the roughness decreased with each tested frequency of laser pulses. It can be also said that the surfaces with lower values of roughness can be produced by using bigger laser power [6].

Another experiment was done by Ackerl et al. [7] where the aim of this experiment was to observe the influence of laser spot overlap (in the axis of the workpiece $(l p)$ and vertically to the axis of the workpiece $(l b)$ ) on the roughness of the final surface. The scheme of both types of overlaps is shown below.

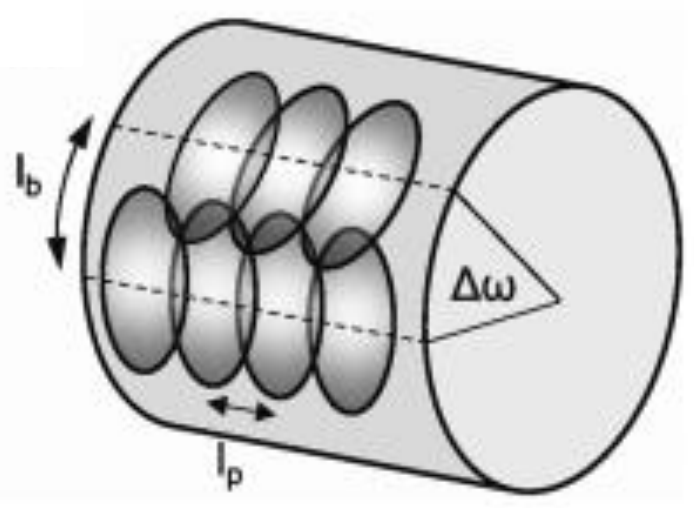

Fig. 1. Two types of overlaps (lb - line overlap; lp - pulse overlap) [7]

They found out that with the increasing value of the laser spot overlap in the axis of the workpiece ( $l p$ - pulse overlap) the roughness of the final surface was better (the value of $R_{a}$ was smaller). For the line overlap applies that with a smaller value of the line overlap ( $l b)$ the surface roughness was better (the value of $R_{a}$ was smaller) [7]. Other parameters that affect tangential laser machining are for example the depth of the cut, the feed rate and the rotational speed (cutting speed) [8]. These parameters are also used in conventional turning [9]. Their influence on the final state of the products is investigated in the experiment of this article.

\section{Experiment}

The aim of this experiment was to find out the relations between the parameter cutting speed and final state of surface roughness $\mathrm{Ra}$, time of the machining process (process time) and the accuracy of the final shape according to the required shape. This experiment was done in the laboratory of the company HOFMEISTER s.r.o. where the company's laser system was used. This device was a femtosecond laser with a wavelength of $515 \mathrm{~nm}$, a laser pulse length of $240 \mathrm{fs}$, a laser spot size of $16 \mu \mathrm{m}$, a frequency of $200 \mathrm{kHz}$ and an average maximum power of $3.2 \mathrm{~W}$. The semi-finished products for the experiment were sintered carbide rods (Grade F06D [10] Table 1) with a diameter of $2 \mu \mathrm{m}$ and a length of $200 \mathrm{~mm}$.

\begin{tabular}{|c|c|c|c|c|c|}
\hline Grade of sintered carbide & grain size $[\mu \mathrm{m}]$ & $\mathrm{C}_{\mathrm{o}}[\%]$ & hardness $(\mathrm{HV} 30)$ & hardness (HRA) & density $\left[\mathrm{g} / \mathrm{cm}^{3}\right]$ \\
\hline F06D & $\leq 0.6$ & 6.0 & 1840 & 93.4 & 14.80 \\
\hline
\end{tabular}

Table 1. Specification of the grade of sintered carbide [10]

This experiment consists of two parts. The first part concerns the preparation of a good initial state of the workpiece. During this first part of the experiment, the semi-finished product is machined via laser to reduce the diameter of the semifinished product from $2 \mathrm{~mm}$ to $1.87 \mathrm{~mm}$ in the length of $6 \mathrm{~mm}$. This diameter reduction is performed due to compensation of the workpiece's radial run-out after its clamping into the laser system. After that, the second part of the experiment follows.

This is the main part of the experiment which aim is to produce material removal with different values of the parameter cutting speed $\left(v_{c}\right)$ (five different values) with a constant value of feed rate per revolution $\left(f_{\text {rev }}\right)$, depth of cut $\left(a_{p}\right)$ and all other laser parameters (diameter of the laser spot, frequency, laser power) to observe the influence of the parameter $v_{c}$ on the roughness of the final surface machined diameter of the workpiece, the accuracy of the final diameter and process time. The removal of the material is from diameter $1.87 \mathrm{~mm}$ to $1.5 \mathrm{~mm}$ to a range of $0.5 \mathrm{~mm}$ which is shown in Fig. 2 . 


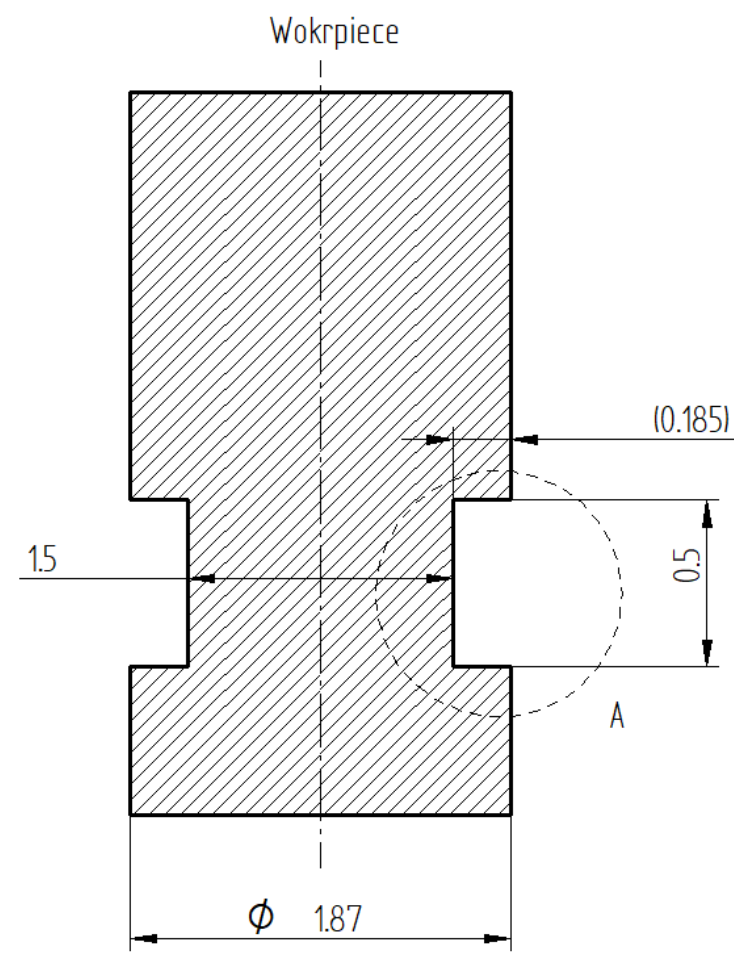

A

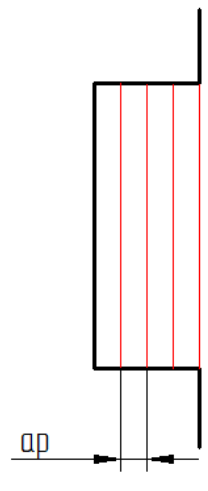

— Laser path

Fig. 2. Scheme of the experiment

This material removal was done by using the laser technology called tangential machining which was described in the previous chapter. The setup of the experiment is shown in Fig. 3.

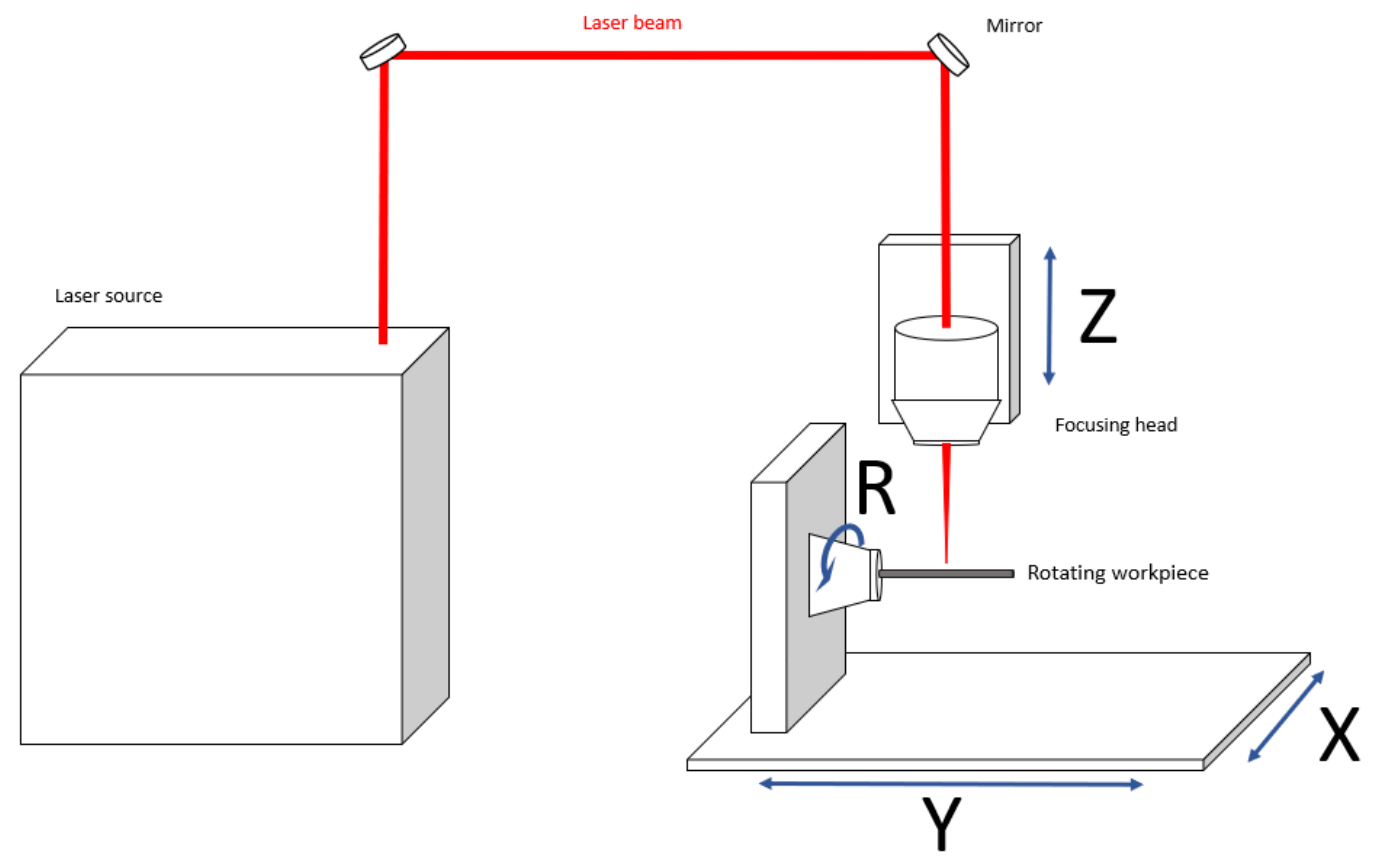

Fig. 3. Experiment setup

The main machining parameters which were used for this experiment are shown in the table below. As for other laser parameters the pulse energy $E_{p}$ was $15 \mu \mathrm{J}$, its value was constant so as not to affect the results.

\begin{tabular}{|c|c|c|}
\hline$v_{c}[\mathrm{~m} / \mathrm{min}]$ & $f_{\text {rev }}[\mathrm{mm}]$ & $a_{p}[\mathrm{~mm}]$ \\
\hline $0.06 ; 0.08 ; 0.1 ; 0.5 ; 0.7$ & 0.025 & 0.005 \\
\hline
\end{tabular}

Table 2. Parameters used for the experiment 


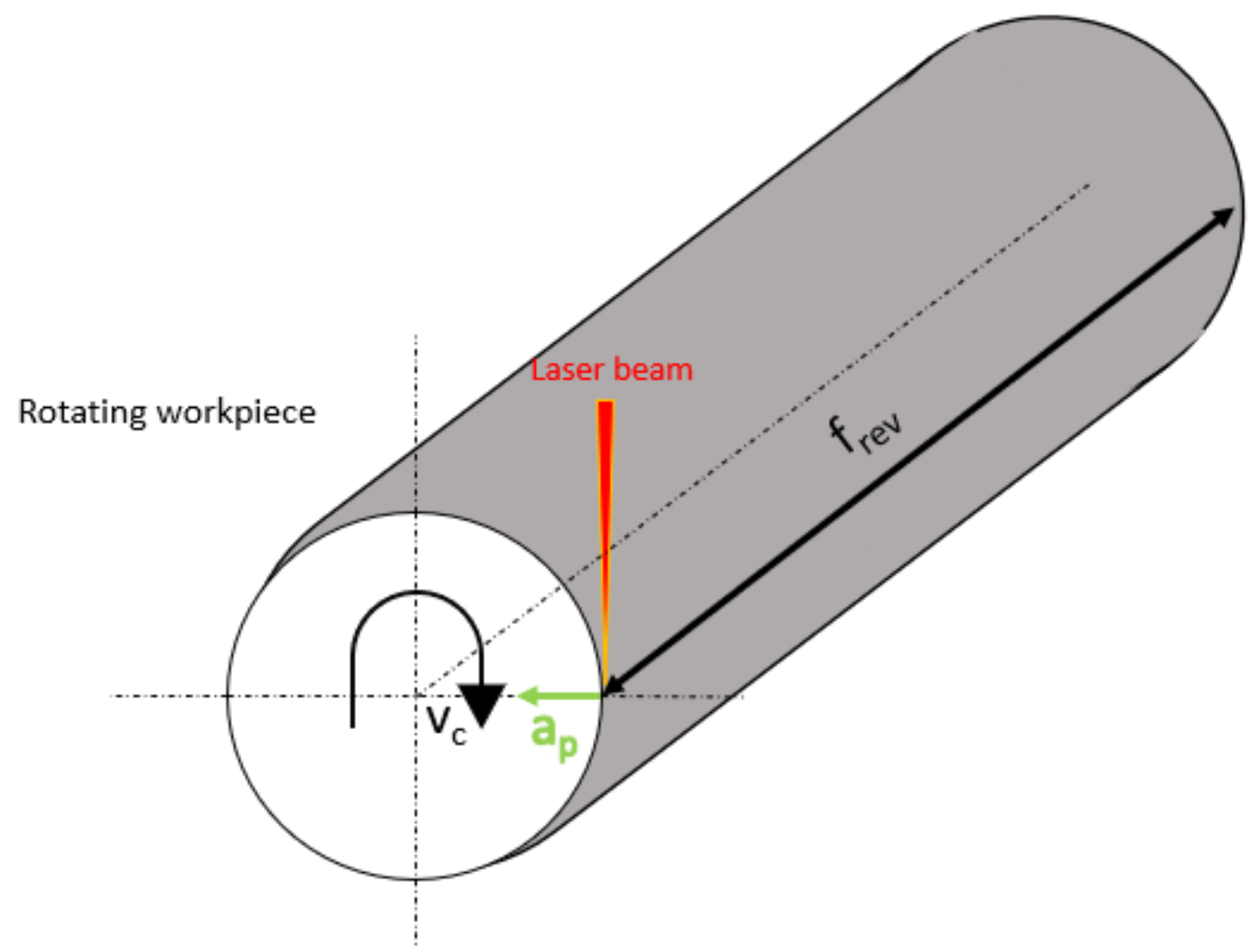

Fig. 4. Scheme of the parameters which were used for the experiment

\section{Results}

The final workpiece was analysed using an Olympus Lext confocal microscope (Fig. 5), where the roughness $R_{a}$ of the resulting surfaces and the accuracy of the manufactured dimensions were measured.

$$
v_{c}=[\mathrm{m} / \mathrm{min}]
$$

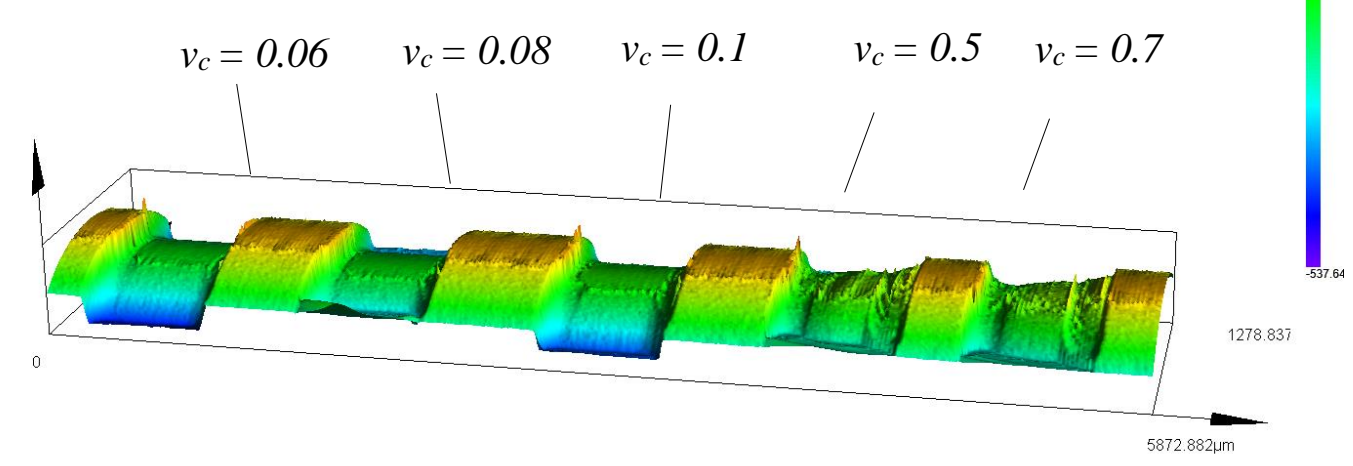

Fig. 5. Scan of final workpiece

The results obtained from the performed experiment via confocal microscope were analysed and inserted into the following graphs. 


\section{Roughness}

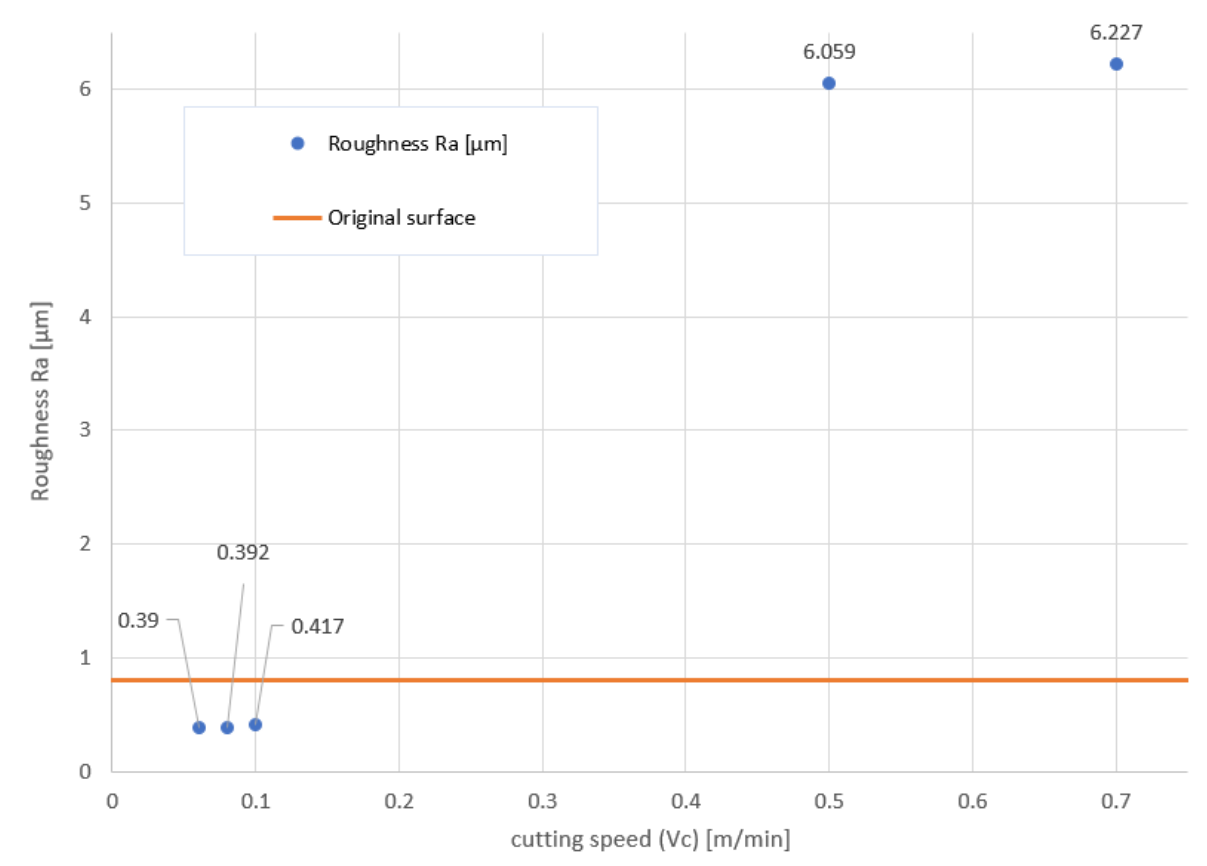

Graph 1. The dependence of the parameter cutting speed $\left(v_{c}\right)$ on the surface roughness

From Graph 1 can be seen that the value of the parameter cutting speed $\left(v_{c}\right)$ has a significant influence on the resulting value of the surface roughness $R_{a}$. It is evident that with the increasing value of $v_{c}$ the value of the resulting surface roughness $\left(R_{a}\right)$ also increased. Furthermore, it can be seen from the graph above that the roughness $R_{a}$ of the resulting surface was lower than the original in the cases where the values of cutting speeds were $0.06 ; 0.08 ;$ and $0.1 \mathrm{~m} / \mathrm{min}$. The lowest achieved surface roughness $R_{a}$ was $0.39 \mu \mathrm{m}\left(v_{c}=0.06 \mathrm{~m} / \mathrm{min}\right)$ and the highest value of surface roughness $R_{a}$ was $6.227 \mu \mathrm{m}\left(v_{c}=0.7 \mathrm{~m} / \mathrm{min}\right)$.

Another quantity that was examined was the size of the resulting workpiece diameter. This quantity is important for the evaluation of the performed experiment in order to determine whether the required dimensions have been achieved by tangential laser micromachining or not. Measurement of the resulting values of workpiece diameters was also done using a confocal microscope and the obtained results were processed in the graph below.

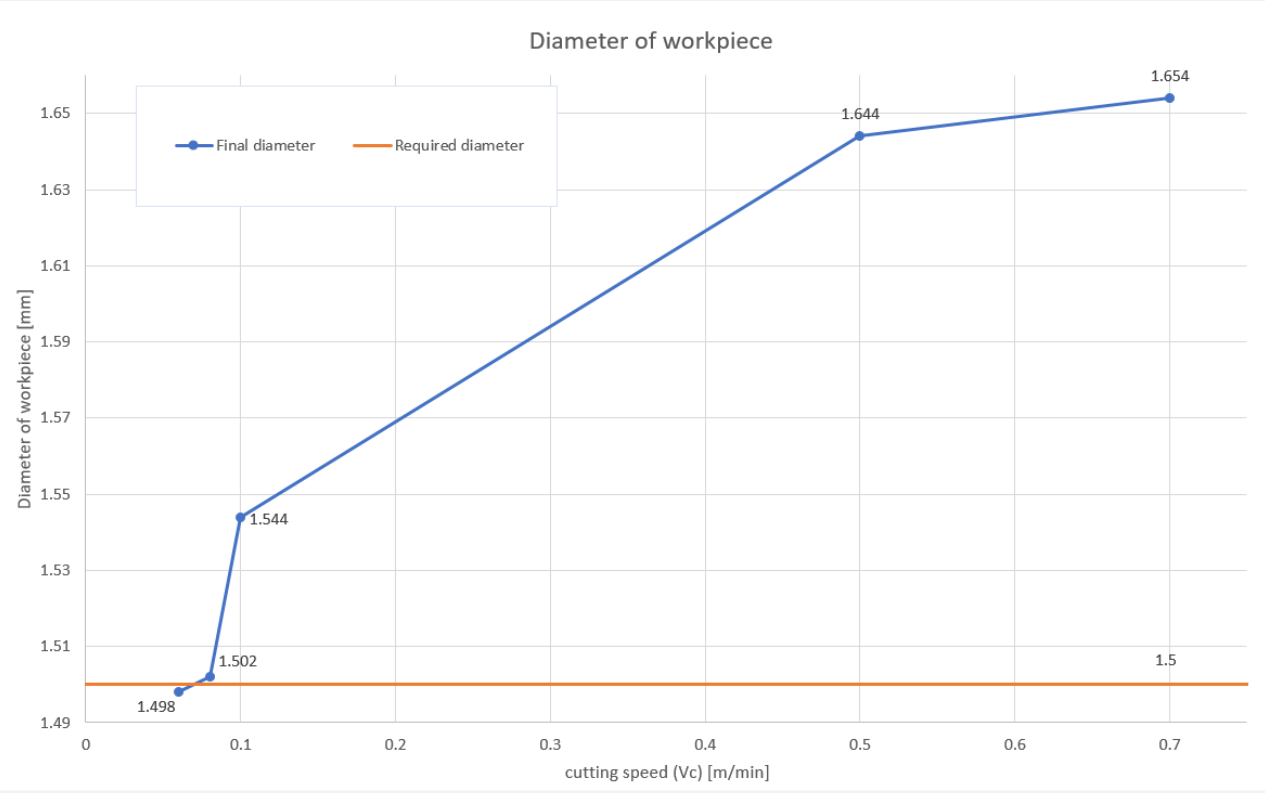

Graph 2. The dependence of the parameter cutting speed (vc) on the value of the diameter of the workpiece 
It can be seen from the graph (Graph 2) that the size of material removal also depends on the value of the cutting speed. Also, it can be observed that with decreasing value of $v_{c}$, the size of material removal increases. The results that most closely resembled the desired shapes were obtained using a low cutting speed. If the value of $v_{c}$ was equal to $0.06 \mathrm{~m} / \mathrm{min}$, the resulting workpiece diameter was measured as $1.498 \mathrm{~mm}$ and for the $\mathrm{v}_{\mathrm{c}}=0.08 \mathrm{~m} / \mathrm{min}$ the final workpiece diameter was measured as $1.502 \mathrm{~mm}$, which means that the deviation of these produced diameters is only $0.002 \mathrm{~mm}$ from the desired size of the final diameter of the workpiece which was $1.5 \mathrm{~mm}$.

The last quantity for which the influence of the value of the cutting speed $v_{c}$ on its size was investigated was the length of the process time. The process time is a very important variable in laser machining but also in other types of machining due to the fact that nowadays the hourly rates of machines are high and every minute of process time can have a big impact on the final price of the product. The values of the process time were determined from the used laser femtosecond device which after each machining process shows its exact duration. The obtained values were put in the following graph.

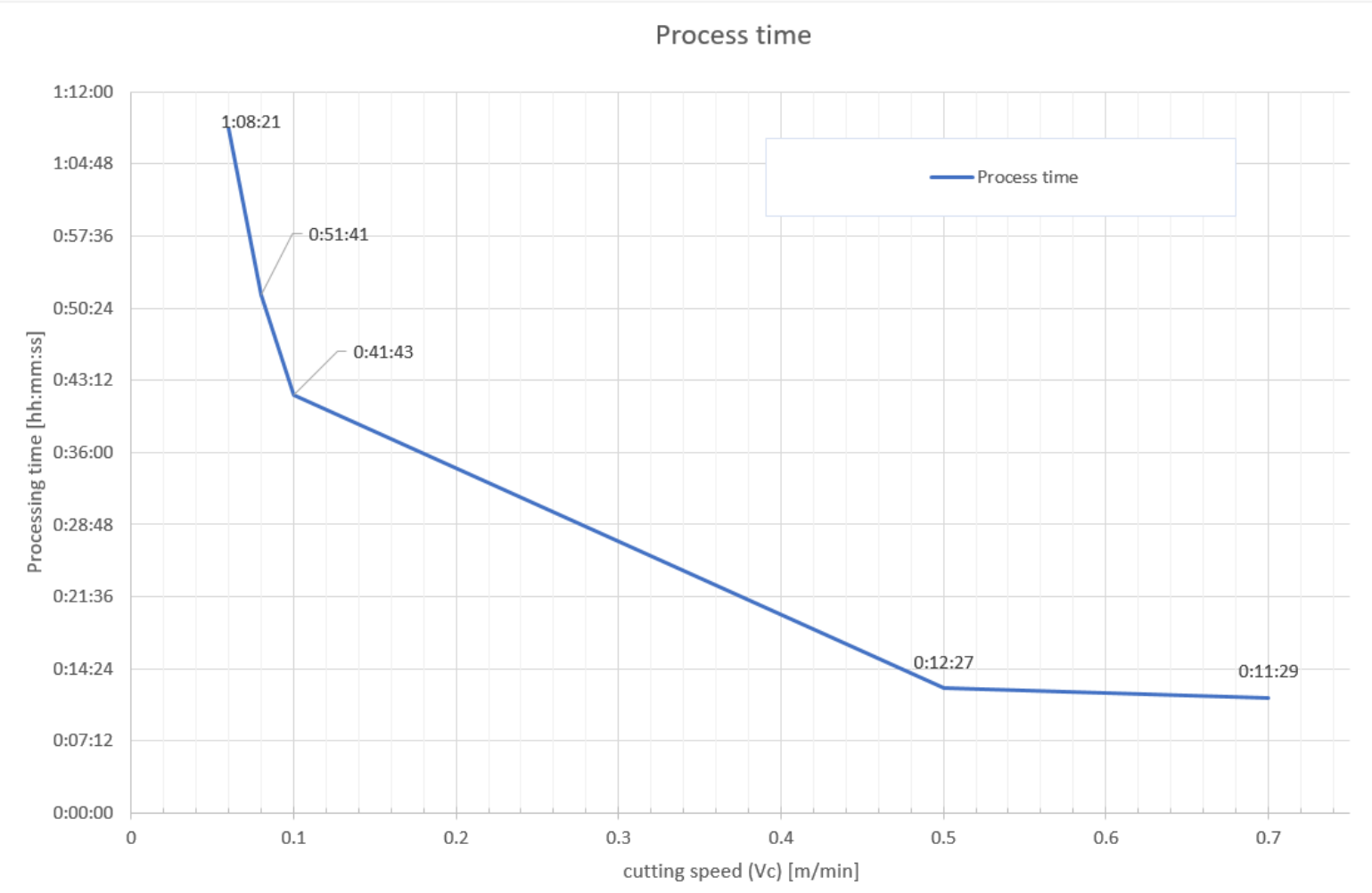

Graph 3. The dependence of the parameter cutting speed (vc) on the length of the process time

Graph 3 showing the relationship between parameter $v_{c}$ and the length of the process time. It can be said that the process parameter $v_{c}$ has an influence on the length of the process time and also it can be seen that the length of the process time increases with decreasing cutting speed. It was found that the fastest production time (00:11:29) was achieved using the cutting speed of $0.7 \mathrm{~m} / \mathrm{min}$.

\section{Conclusion}

Based on the performed experiment, which contained the tangential laser micromachining of sintered carbide rods, the effects of cutting speed on the final parameters of the workpiece were investigated therefore other process parameters were constant. The investigated parameters were the surface roughness $R_{a}$, the accuracy of the final shape and the length of the process time. It was found that all of these parameters are affected by the setting of the cutting speed. Regarding the dependence of the length of the process time on the cutting speed, it was found that the higher values of the cutting speed shorten the process time (the fastest process time was $11 \mathrm{~m} 29 \mathrm{~s}$ for used cutting speed equal to $0.7 \mathrm{~m} / \mathrm{min})$. However, with this high cutting speed, a surface with a high roughness $R_{a}(6.227 \mu \mathrm{m})$ was created and the final diameter of the workpiece did not correspond to the required (the deviation from the required shape was $0.154 \mathrm{~mm}$ ). It is possible, despite the very short process time, high cutting speeds are not suitable for the production of microscopic entities. When using a low cutting speed $\left(v_{c}=0.06 \mathrm{~m} / \mathrm{min}\right)$, a surface with a small roughness $R_{a}(0.39 \mu \mathrm{m})$ was produced and the deviation of the accuracy of the produced workpiece diameter from the required one was only by $0.002 \mathrm{~mm}$. But the length of the process time was very long $(1 \mathrm{~h} 08 \mathrm{~m} 21 \mathrm{~s})$. It can therefore be said that when using low cutting speeds, the result is a very precise shape with good surface roughness Ra but the process is not effective due to long process times. 
The value of the executed experiment is that it was successfully put into operation the tangential laser machining on the laser system from HOFMEISTER s.r.o. and that limits on cutting speed values have been tested. Another possible continuation of this experiment could be to try a wider range of cutting speed values or to investigate the influence of other laser parameters on the tangential laser micromachining process.

\section{Acknowledgments}

This article was created under the project SGS-2019-008: Research and Development for Innovation in the Field of Manufacturing Technology - Machining Technology III.

\section{References}

[1] L. Orazi, L. Romoli, M. Schmidt, and L. Li. (2021). 'Ultrafast laser manufacturing: from physics to industrial applications', CIRP Ann., vol. 70, no. 2, pp. 543-566, 2021, doi: 10.1016/j.cirp.2021.05.007.

[2] G. Raciukaitis. (2021). 'Ultra-Short Pulse Lasers for Microfabrication: A Review', IEEE J. Sel. Top. Quantum Electron., vol. 27, no. 6, pp. 1-12, Nov. 2021, doi: 10.1109/JSTQE.2021.3097009.

[3] M. Hajri, J. Pfaff, H. Büttner, M. Voegtlin, R. Kaufmann, and K. Wegener. (2018). 'Fabrication of a ball end nose micro milling tool by tangential laser ablation', Procedia CIRP, vol. 77, pp. 654-657, 2018, doi: 10.1016/j.procir.2018.08.184.

[4] J. Zettl, C. Esen, M. Klar, and R. Hellmann. (2020). 'Generation of Rotationally Symmetric Micro Tools using Ultrashort Laser Pulses’, J. Laser MicroNanoengineering, Sep. 2020, doi: 10.2961/jlmn.2020.02.2007.

[5] M. Warhanek, C. Walter, M. Hirschi, J. Boos, J. F. Bucourt, and K. Wegener. (2016). 'Comparative analysis of tangentially laser-processed fluted polycrystalline diamond drilling tools’, J. Manuf. Process., vol. 23, pp. 157-164, Aug. 2016, doi: 10.1016/j.jmapro.2016.06.023.

[6] G. Kibria, B. Doloi, and B. Bhattacharyya. (2017). 'Laser Micro-turning Process of Aluminium Oxide Ceramic Using Pulsed Nd:YAG Laser', in Non-traditional Micromachining Processes, G. Kibria, B. Bhattacharyya, and J. P. Davim, Eds. Cham: Springer International Publishing, 2017, pp. 179-226. doi: 10.1007/978-3-319-52009-4_5.

[7] N. Ackerl, M. Warhanek, J. Gysel, and K. Wegener. (2019). 'Ultrashort-pulsed laser machining of dental ceramic implants', J. Eur. Ceram. Soc., vol. 39, no. 4, pp. 1635-1641, Apr. 2019, doi: 10.1016/j.jeurceramsoc.2018.11.007.

[8] D. Sriram, G. Jayaprakash, D. Arulkirubakaran, M. Prabu, and A. Ajithkumar. (2021). 'Laser turning of alumina (A12O3) ceramic by Nd:YAG laser technique', Mater. Today Proc., vol. 39, pp. 731-735, 2021, doi: 10.1016/j.matpr.2020.09.405.

[9] W. Zębala, R. Kowalczyk, and A. Matras. (2015). 'Analysis and Optimization of Sintered Carbides Turning with PCD Tools', Procedia Eng., vol. 100, pp. 283-290, 2015, doi: 10.1016/j.proeng.2015.01.369.

[10] D. F. Ilgen. (2020). 'Catalogue for Carbide Rods', p. 24, 2020, [Online]. Available: https://pcggmbh.de/default.asp?kat=193\&ukat=262\&lang=eng 